dent fevers. It is believed by many, that the kausos of Hippocrates, which has been so elegantly commented on by the learned Cappadocian, was no other than the ende. mic fever that is of such frequent and fatal occurrence in and near the tropics. It often begins with intense headach; and delirium, in many instances, supervenes; but in a greater number of cases, the stomach, from the beginning, is excessively irritable, and the head suffers propurtionately less; but when this affection of the head does take place, even in the highest degree, it is but indicative of great irritation of the biliary apparatus, accompanied by phlegmonous inflammation of the stomach, and not unfrequently of part of the intestines. This opinion has not been hastily formed, but is founded on twelve years' extensive practice in a country that was every year visited, more or less severely, by the puretoi kausoi under various modifications, but never taking on the character of idiopathic brain fever.

In many instances, where a considerable degree of delirium has been present in the early part of the disease, the acute symptoms go off, the skin assumes a fish-like coldness, reason is again seated on her throne, and the patient flatters himself with hopes of a speedy recovery, while to all around him, he is evidently sinking into the arms of death. In this stage of the disease, patients speak of persons and things, with which mere accident (particularly if assisted by a little of the marvellous) may furnish some curious coincidences; but I cannot say that any thing has come under my own immediate observation, which could, in any way, be connected with a "spirit of prophecy." It is true, nevertheless, that I have heard of an old woman of Massachusetts, in North America, having foretold in one of those "lightnings up before death," that Providence would, on a certain day, step out of its way, and so far reverse the laws of Nature, as to render another old woman perceptible of spontaneous combustion. It will be proper to state, that although this prophetess had escaped all suspicion of witcheraft during her life-time, she was heard, before making the above communication, to pronounce the word abraxa, and that after ber death, the letters $A B R A C$ were found marked in gunpowder over the region of the heart. Moreover, on tracing her genealogy, she was found to have descended in a right line from one of the magicians of Pharaoh, who changed the rods into serpents, and the waters of the Nile into blood; and it was discovered also, that one of her ancestors had married the witch of Endor, who called up the ghost of Samuel at the request of Saul.

Cheltenham, March 21 st, 1830.

\section{PTYALISM FROM MINUTE DOSES OF CALOMEI.}

$$
\text { By James Bind, Esq., M.R.C.S. }
$$

IN the month of April, 1827, I was in attendance on an unmarried female, about 26 years of age, who was suffering from spasmodic retention of urine. She had been many years an invalid, and had suffered severely from a spinal affection, the greater part of two of the lumbar vertebræ being completely destroyed by caries. She had been under the care of an eminent surgeon in a neighbouring city, whilst suffering under the acute form of her disease, and under his treatment had received as much relief as enabled her to follow her occupation as a needle-woman, moving about without much pain or difficulty, although her movements clearly indicated the loss of support behind. When I first saw her she was suffering, as I have named, from spasmodic retention of urine and an almost complete state of atomy of the whole contents of the pelvis, bladder, uterus, and rectum, being alike affected; in short, when either of the above-named viscera required to be relieved, she was for some time a perfect mass of spasm. She was under my care a considerable time, and every mode of relief I could devise, had a very fair, though, I am sorry to add, a far from satisfactory trial. The greatest relief was obtained by mechanical means; the regular use of the catheter, with opiate and purgative injections into the rectum, as the symptoms required. By a diligent use of the above, she was restored to the state she was in previous to her coming under my care; but I fear her diseased spine precludes the hope of her being relieved for any permanency. In the treatment of this case, I prescribed amongst others the following: a scruple each of mercurial pill, squill pill, and the compound gamboge pill, mixed well together, and divided into twelve pills, and directed one to be taken every six hours. Five pills only had been taken, when all the symptoms of mercurial salivation presented themselves, and for fourteen days, her mouth, gums, and the glands about the throat, were affected in the most severe and distressing manner. She had taken no mercury for some time previously, so I conclude all these symptoms were the result of the composition I have named.

The second instance occurred in a married lady, about a week subsequent to her confinement, and who was suffering a litile from a bilious diarrhoea. I gave her three grains of calomel, and ten grains of rhubarb powder, followed up by a litlle cordial spirit in cinnamon water. The diarrhoa certainly was checked, but mercurial salivation supervened, that lasted for four or five days. In each of these cases I have termed it mer- 
curial salivation, the futor of the breath/at half-past ten; between one and two clearly indicating the effects of the mineral o'clock a glyster of the infusion of tobacco, on the system.

I could enumerate other instances, but perhaps they might be a little more equivo. cal than the cases related above. 1 have been induced to make this communication for the purpose of adding my testimony to the very clear case of $\mathrm{Mr}$. Clayton, that such effects are produced by a very small portion of mercury ; and I believe they are more frequent than is generally credited. I think also, that every case that is un. common, or that presents any new feature in our practice, deserves do be communicated, if only to point out a few amongst the many shoals and quicksands upon which professional reputation may be wiecked.

This much I beg te observe in conclusion, that in no instance in which this almost spontaneous salivation has occurred, have 1 observed it operate unfavourably on the constitution; indeed, from what I have seen, I am inclined to attribute it as much to an effort of nature for throwing off more serious disease, as vomıting, sweatıng, discharge by urine or diarrhoca.

Cardiff, South Wales,

March 20 th, 1830.

\section{DERBYSHIRE GENERAL INFIRMARY.}

CASE OF AN OLD WOMAN WHO IIAD "A KNOB AT THE SIDE OF HER BELLY."

Erazabers Woodwand, wat. 68, was sent into this Infirmary on Sunday, Feb. 28, 1830, at about half past ten A.M. She came under the treatment of Mr. Godwin as surgeon for the week.

The case is entered in the book as one of "strangulated femoral hemia" on the right side. IVe believe the symptoms were not very urgent. The patient's bowels were much constipated, but alvine evacuations could not be considered suppressed; we hear she had a stool on the Friday night previous to her admission, viz. the day but one before; we believe the woman was not aware of having had a rupture; but when asked if she had " a lump at the top of her thigh," she said she had, but how long this "lump" had existed we know not. She is described as having had pain in the abdomen, and sickness; no "vomiting of facal matter." "I be day before she was sent to the Infirmnry, opening medicine and a glyster were administered, without the bowels being moved.

This ease, called " strangulated hernia," arrived at the Infirmary (as we have said) and a cold lotion to the tumour, were prescribed by the surgeon; these, we believe, were the only remedies used: we, of conrse, presume the taxis was tried.*

A consultation had been called (by notes sent to the surgeons only) for four o'clock, with a view to performing the operation, if decided upon. Mr. Godwin came much after the time he had appointed, and the operation for "strangulated hernia" was com. menced at half-past five P.M. by candle-light, seven hours after the admission of the patient, which time was not occupied by trying all the usual measures for obtaining the return of a hernia. Mr. Wright, one of the staff, attended, with a few others, at the operation.

Mr. Godwin, after professing to have got down to the sac, and after various attempts to cut into this sac, said the intestine is so "intimately adherent to the sac, that it is impossible to open the sac!" He proceeded, therefore, to divide various strictures in different directions, of course exterior to the sac. Something was said about a double hernia, and $a$ band between the two, which required dividing with the knife. Attempts were now made to force the sac, and its supposed adherent contents, into the cavity of the abdomen, and the patient suffered much pain during these trials. The sac would not enter the abdomen, although va. rious strictures had been divided. Some persons said the hernia was reduced by the taxis during the operator's efforts to return the sac. What became of "the intimate adhesions," if this were true? Some said the tumour, or sac, became less during the operatoı's efforts; others saw no alteration in bulk. Mr. Godwin having done the opetion in twenty-five minutes, sewed up the wound.

The bowels became open in three hours after the operation, and again in the night. (Mr. Dix has entered in Mr. Godwin's Casebook-"Stool fourteen hours after the operation." We can only account for this, by saying Cerber us Dix is ***) Abdomen painful and tender. The application of leeches was suggested, inflammation being suspected; but Mr. Godwin objected to the practice, although the belly was very hot, very hard, and tender. On Wednesday afternoon, three days after the operation, the patient expired ; and " Mr. Godwin's experience led him to believe, that the intestine had sphacelated."

* We are anxious to know how long the glyster was retained, and whether it had any effect on the bowels, or on the constitution in producing collapse?-REP. 